\title{
Conquistas e retrocessos do direito à educação: nas legislações e propostas de formação de professores
}

\author{
Achievements and setbacks of the right to education: in legislation and \\ teacher education proposals
}

\begin{abstract}
Adriana Cabral Pereira de Araujo Mestre em Educação pela Faculdade de Formação de Professores da Universidade do Estado do Rio de Janeiro FFP/UERJ. Professora de disciplinas pedagógicas do curso normal da Secretaria de Estado de Educação do Rio de Janeiro. Itaboraí, Rio de Janeiro, Brasil. Professora Orientadora Pedagógica da Prefeitura Municipal de São Gonçalo. Rio de Janeiro, Brasil. adriacabral2012@gmail.com
\end{abstract}

\begin{abstract}
Vania Finholdt Angelo Leite
Doutora em Educação pela Pontifícia Universidade Católica do Rio de Janeiro - PUC-Rio. Professora adjunta da Faculdade de Formação de Professores da Universidade do Estado do Rio de Janeiro e do quadro permanente do Programa de pós-graduação em Educação: Processos formativos e desigualdades sociais. São Gonçalo, Rio de Janeiro, Brasil. vfaleite@uol.com.br
\end{abstract}

Resumo: O ensaio analisa as legislações brasileiras a partir de 1988, as propostas de formação de professores verificando em que medida elas respeitam a criança como sujeito de direitos. Para tal, o córpus de análise foi composto pelas legislações (Constituição Federal de 1988; Lei nº 9.394/1996; PNE 20142024; EC no 95/2016), pelo Referencial Curricular Nacional da Educação Infantil; Diretrizes Curriculares Nacionais da Educação Infantil e o programa Proinfantil. Por meio da análise percebemos que houveram avanços do direito da criança na Constituição Federal de 1988 pela obrigatoriedade e gratuidade da educação, assim como na lei 9.394/1996 que definiu a Educação Infantil como primeira etapa da educação básica. Notamos, ainda, que a proposta do Proinfantil respeita a criança e seus direitos, ao propor práticas pedagógicas que incluam, ouçam e respeitem a criança, como ser participativo, ativo, criativo, produtor de culturas, reconhecendo-a como atores sociais de pleno direito.

Palavras-chave: Direito a educação. Formação de professores. Infâncias.

\begin{abstract}
The essay analyzes Brazilian legislation from 1988 onwards, the proposals for teacher training, verifying to what extent they respect the child as a subject of rights. For this purpose, the analysis corpus was composed of the laws (Federal Constitution of 1988; Law no 9.394 / 1996; PNE 2014-2024; EC n ${ }^{\circ}$ 95/2016), by the National Curriculum Reference of Early Childhood Education; National Curriculum Guidelines for Early Childhood Education and the Proinfantil program. Through the analysis we realized that there were advances in the right of the child in the Federal Constitution of 1988 due to the mandatory and free education, as well as in the law 9.394 / 1996 that defined Early Childhood Education as the first stage of basic education. We also note that the Proinfantil proposal respects children and their rights, by proposing pedagogical practices that include, listen to and respect the child, as a participative, active, creative, cultural producer, recognizing them as full social actors.
\end{abstract}

Keywords: Childhood. Right to education. Teacher education. 
ARAUJO, Adriana Cabral Pereira; LEITE, Vania Finholdt Angelo. Conquistas e retrocessos do direito à educação: nas legislações e propostas de formação de professores

\section{Introdução}

O presente ensaio aborda as conquistas do direito à educação implementadas a partir da Constituição Federal (CF) de 1988, e aponta os desafios e avanços enfrentados pela Educação Infantil nesses 30 anos. Reconhecemos que foi um longo caminho percorrido, desde as ações assistencialistas oriundas das creches até a promulgação da CF 1998, que traz o reconhecimento e a garantia da educação como direito da criança. Embora este marco legal represente um avanço, defendemos que não é suficiente para que se efetive uma prática que respeite o tempo de ser criança, as suas especificidades e os direitos de aprender através das brincadeiras e das interações sociais, vivenciando múltiplas experiências e linguagens no cotidiano da Educação Infantil. É necessário, para tanto, que a formação inicial e continuada contemple essas questões durante a formação e considere que as professoras são produtoras de saberes e conhecimentos.

Ao problematizar esta discussão com o referencial teórico de Sarmento (2007), observamos que apesar de alguns avanços as crianças continuam sendo um grupo social fortemente afetado pelas desigualdades sociais e ineficiências de políticas públicas.

Nos apoiamos, ainda, em pesquisas anteriores sobre o direito da criança, tais como: Rosemberg e Mariano (2010), Abramowicz e De Oliveira (2017), Arelaro (2017) para levantar os questionamentos que norteiam este ensaio. Partimos, portanto, das seguintes questões: quais avanços podem ser destacados a partir da conquista do direito à educação? Quais são as políticas públicas educacionais que garantem o direito à educação da criança nesses 30 anos? Será que as formações de professores proposta a partir das reformas neoliberais respeitam as crianças como sujeito de direitos? O córpus é composto pelas legislações (CF de 1988; Lei no 9.394/96; PNE 20142024; EC n. 95/206), pelos documentos Referencial Curricular Nacional de Educação Infantil (RCNEI); Diretrizes Curriculares Nacionais Educação Infantil (DCNEI) e pelo programa Proinfantil.

Para responder às questões norteadoras desse ensaio, estruturamos o texto nos seguintes tópicos: I) na primeira parte, de forma breve, descrevemos o percurso histórico das legislações no Brasil, a partir de 1988. Com isso, apontamos os avanços e retrocessos em relação aos direitos a Educação Infantil; II) na segunda parte, apresentamos uma discussão a respeito das concepções de formação de professores a partir de 1990, buscando analisar se as propostas de formação respeitam a criança como sujeito de direitos e, por fim, III) retomamos as questões norteadoras a fim de fazer algumas considerações acerca das discussões apresentadas. 
ARAUJO, Adriana Cabral Pereira; LEITE, Vania Finholdt Angelo. Conquistas e retrocessos do direito à educação: nas legislações e propostas de formação de professores

\section{Breve histórico das legislações: avanços e retrocessos}

Ao pensarmos na Educação Infantil brasileira, se faz importante, voltar o olhar para o lugar destinado à criança e às concepções implicadas no seu atendimento. Durante muitos anos, a inexistência de políticas públicas de atendimento à infância marcou a dura realidade das crianças. Nessa perspectiva, Marcílio (1997, p. 51) aponta que "a roda dos expostos foi uma das instituições brasileiras de mais longa vida, sobrevivendo aos três grandes regimes de nossa história", ou seja, foi iniciada no Brasil Colônia e extinta somente em 1950. Assim, ao analisar esses longos 224 anos de duração da roda dos expostos no país, percebemos a escassez de um atendimento e de uma política pública que, de fato, considerasse as crianças e suas especificidades.

As políticas públicas voltadas às crianças estiveram durante muito tempo atreladas às ações assistencialistas presentes nas creches. Esse atendimento promovido por profissionais ligados a área da saúde abrangia apenas o aspecto físico da alimentação e higiene nos cuidados das crianças da classe social pobre, que, por serem menos favorecida, careciam da benevolência e da guarda num atendimento que era visto como possiblidade de compensar o seu déficit nutricional, social e cultural.

Posteriormente, com o crescimento do processo de industrialização e a inserção das mulheres no mercado de trabalho, indústrias promoveram "a criação de vilas operárias no interior das fábricas, com habitação, creches, escolas maternais e assistência médica, é a estratégia adotada por empresários interessados em não sofrer descontinuidade em sua linha de produção (...)" (KISHIMOTO, 1990, p. 60).

Assinalamos que das ações higienistas e assistencialistas existentes nas creches até a garantia da educação das crianças pequenas como um direito conquistado, foi uma caminhada extensa, marcada por intensas lutas do movimento de mulheres trabalhadoras, sindicatos e universidades. Essa longa luta promovida nos movimentos sociais reverberou na garantia da conquista do direito à educação na CF de 1988.

Outras políticas públicas de atendimento às crianças e suas especificidades foram surgindo a partir de 1988, dentre elas a criação do Estatuto da Criança e do Adolescente (ECA) em 1990. O surgimento dessa e de outras legislações aponta uma mudança conceitual no que se refere à compreensão e ao atendimento das especificidades das crianças. Segundo o ECA, em seu artigo $4^{\circ}$, “é dever do poder público assegurar o direito das crianças e dos adolescentes à educação". Já o artigo $54^{\circ}$, inciso IV, expressa que "é dever do estado assegurar à criança o atendimento em creche e pré-escola às crianças de 0 a $6 \operatorname{anos}^{1}$ de idade". 
No entanto, mesmo depois de tantos anos da implementação do ECA, notamos que esse direito de fato não ocorre em algumas cidades brasileiras. No caso da cidade do Rio de Janeiro, percebemos que não há efetivação das matrículas na Educação Infantil. Segundo informações de Vieira da Agência Brasil de 20/01/2018: "Nas contas da defensoria, há um déficit de 35 mil vagas na cidade do Rio, o que a prefeitura nega. A Justiça também estabeleceu que sejam construídas mais creches e pré-escolas para atender a procura”. Essas informações apontam o grande número de crianças que estão sendo cerceadas no seu direito básico à educação.

Outro avanço a ser destacado foi a $\operatorname{LDB} \mathrm{n}^{\circ}$ 9.394/96, que aponta a consolidação da garantia desse direito. A Educação Infantil passou a se configurar como a primeira etapa da educação básica reforçando o legado, quanto ao direito à educação, deixado pela CF de 1988. Na seção II, o Artigo $29^{\circ}$ da LDB institui que a finalidade principal da Educação Infantil é "o desenvolvimento integral da criança de até seis anos, ${ }^{2}$ em seus aspectos físico, psicológico, intelectual e social, complementando a ação da família e da comunidade. (BRASIL, 1996).

Essas mudanças apresentadas nesse dispositivo legal que ressaltam o reconhecimento e valorização das especificidades da infância e da sua formação integral provocaram reflexões em relação ao seu atendimento. $\mathrm{O}$ artigo $4^{\circ}$, inciso IV, da LDB aponta como dever do estado a garantia do "atendimento gratuito em creches e pré-escolas às crianças de zero a seis anos de idade" (BRASIL, 1996). Concordamos com Cury (1998), que esse novo olhar para as infâncias significa um rompimento, mesmo que não absoluto, com a lógica do amparo e da assistência no atendimento às crianças pequenas.

Porém, torna-se importante sinalizar que desde a sua promulgação a LDB, sofreu algumas alterações, dentre elas a proposta na lei no 12.796 de 4 de abril de 2013 que trata da obrigatoriedade da matrícula das crianças a partir de 4 anos de idade, e dispõe sobre a frequência obrigatória de, no mínimo, 60\% das 800 horas estabelecidas para os 200 dias letivos. Esta legislação representa, por um lado, um avanço na educação das crianças de 4 e 5 anos, mas, por outro, um retrocesso ao separar o atendimento das crianças na Educação Infantil, não alcançando nessa medida as crianças de 0 a 3 anos.

Outro avanço na garantia dos direitos da criança foi a publicação dos RCNEI em 1998. Criado com o objetivo de orientar os profissionais que atuam nessa faixa etária sinalizaram também a responsabilidade da sociedade e o papel do estado para com as crianças, compreendendo-as agora como sujeitos de direito à educação: 
Modificar essa concepção de educação assistencialista significa atentar para várias questões que vão muito além dos aspectos legais. Envolve, principalmente, assumir as especificidades da educação infantil e rever concepções sobre a infância, as relações entre classes sociais, às responsabilidades da sociedade e o papel do Estado diante das crianças pequenas (BRASIL, 1998, p. 17).

Assumir as responsabilidades com o atendimento à pequena infância, reconhecendo suas especificidades e seu direito à educação, envolve mudanças que vão muito além da ocorrida no texto da lei. Nesse processo de tensões e mudanças, marcado pela transição dos aspectos e concepções de infâncias e pela busca da qualidade no atendimento voltado à infância, os RCNEI apresentam os princípios que norteiam e direcionam as práticas pedagógicas na Educação Infantil, tais como o respeito às crianças e aos seus direitos. Além disso, ele reconhece suas diferenças sociais, econômicas, culturais, étnicas, religiosas, o direito a brincadeira e a liberdade nas suas formas de expressão e interação.

No ano de 2006, em substituição ao FUNDEF foi criado o Fundo de Manutenção e Desenvolvimento da Educação Básica e Valorização dos Profissionais de Educação (FUNDEB) pela Emenda Constitucional (EC) no 53/2006. O novo fundo incluiu todas as etapas e modalidades da educação básica, passando a Educação Infantil a ter direito aos recursos financeiros do governo de acordo com as matrículas nas escolas públicas e conveniadas, apuradas no Censo Escolar realizado pelo Instituto Nacional de Estudos e Pesquisas Educacionais (INEPE).

No ano de 2009, o direito à educação é reafirmado no Artigo $5^{\circ}$ das DCNEI, como apresentado na citação abaixo:

A Educação Infantil, primeira etapa da Educação Básica, é oferecida em creches
e pré-escolas, as quais se caracterizam como espaços institucionais não
domésticos que constituem estabelecimentos educacionais públicos ou privados
que educam e cuidam de crianças de 0 a 5 anos de idade no período diurno, em
jornada integral ou parcial, regulados e supervisionados por órgão competente
do sistema de ensino e submetidos a controle social (BRASIL, 2009).

A aprovação das DCNEI constitui outro avanço nas políticas públicas acerca da garantia do direito à educação das crianças. Isto porque as diretrizes reconhecem as especificidades e as características próprias de ser criança, bem como a valorização do brincar e das interações como fio condutor das práticas cotidianas. Segundo o parecer CNE/CEB no 22/1998, que homologa a criação das DCNEI, as crianças "são seres humanos portadores de todas as melhores potencialidades da espécie" (BRASIL, 1998, p. 6). O documento ressalta, ainda, que as propostas voltadas para a educação infantil "precisam assegurar que não haja uma antecipação de rotinas e procedimentos comuns às classes de Educação Fundamental, a partir da $1^{\mathrm{a}}$ série, mas que não 
seriam aceitáveis para as crianças mais novas” (BRASIL, 1998, p. 6). Dessa forma, a concepção de infância definida pela legislação se traduz no respeito ao tempo da criança, suas vivências e sua formação integral. Observamos, essa concepção de criança explicitado no artigo $4^{\circ}$ da resolução $n^{\circ}$ 5, de 17 de dezembro de 2009 das DCNEI:

As propostas pedagógicas da Educação Infantil deverão considerar que a criança, centro do planejamento curricular, é sujeito histórico e de direitos que, nas interações, relações e práticas cotidianas que vivencia, constrói sua identidade pessoal e coletiva, brinca, imagina, fantasia, deseja, aprende, observa, experimenta, narra, questiona e constrói sentidos sobre a natureza e a sociedade, produzindo cultura (BRASIL, 2009).

Sendo assim, a concepção de infância presente nas DCNEI reconhece a criança como ator social, como sujeito de direitos, ativo, criativo e produtor de cultura. Além disso, ela revela alguns princípios de valorização e reconhecimento das especificidades da criança, princípios estes que dialogam com os conceitos defendidos pela sociologia da infância, e compreendem as infâncias como uma construção cultural, histórica e social (SARMENTO, 2005). Logo, percebemos que nas DCNEI as crianças são compreendidas como atores sociais competentes que integram essa categoria geracional da infância e, nela, imprimem suas especificidades e seu modo próprio de produzir e consumir cultura.

Em 2014, a lei no 13.005 de junho de 2014 aprovou o II Plano Nacional de Educação (PNE) $)^{3}$ (2014-2024). O mesmo prevê como meta 1 a universalização da Educação Infantil na préescola para crianças de 4 a 5 anos, até 2016, e a ampliação do quantitativo de vagas nas creches para o mínimo de 50\% (cinquenta por cento) das crianças de até 3 anos, o que deverá acontecer nas unidades municipais de todo país até o final da vigência deste PNE. No entanto, a universalização não foi alcançada como é evidenciado pelos dados do observatório do PNE:

Desde 2001, observa-se um crescimento constante na porcentagem dessas crianças na Educação Infantil, tendo atingido a marca de 90,5\% em 2015 segundo dados da PNAD. Desse modo, em números absolutos, aproximadamente 4,9 milhões das crianças brasileiras neste intervalo de idade estão na pré-escola. Nos últimos 2 anos, de 2013 para 2015, o indicador avançou 2,6 pontos percentuais, o que aponta que a Meta, que estipula a universalização do acesso para a Educação Infantil, provavelmente não será cumprida.

Esses dados reverberam o não cumprimento da garantia do direito à educação previsto na lei e podem ser percebidos com maior clareza quando voltamos a nossa discussão para São Gonçalo, um município situado no leste metropolitano fluminense do estado do Rio de Janeiro. Trata-se de uma cidade com mais de 1 milhão de habitantes, o que a configura como a $2^{\mathrm{a}}$ maior 
cidade do Estado e a $16^{a}$ cidade do Brasil. Quanto aos equipamentos de Educação Infantil na oferta de vagas, segundo dados do observatório do PNE o município possuía, em 2016, o quantitativo de 25 creches públicas e 170 creches na rede privada. Possui carências no atendimento à sua população em vários aspectos, principalmente nos voltados para a educação da primeira infância.

No que se refere a pré-escola, 69 escolas da rede pública atendem crianças de 4 e 5 anos, ao passo que 236 equipamentos que atendem a pré-escola pertencem a rede privada. Face a essa realidade, destacamos que a ampliação de vagas na rede pública ainda está muito aquém da real necessidade, visto que não há unidades municipais de ensino suficientes para garantir o direito educacional à sua população de 0 a 5 anos de idade.

Os dados publicados no Censo Escolar da educação básica 2016 demonstram que em todo o país houve a redução no número de pré-escolas (de 106.204, em 2016, para 105.200, em 2017) e de Educação Infantil (de 117.191 para 116.472). No entanto, houve um crescimento na quantidade de creches, que passaram de 65.249 para 67.902. Isso não significa um avanço, porque há precariedade na estrutura dessas creches, como indica o Censo (2017) em 61\% tem banheiro adequado à Educação Infantil e apenas 34\% tem berçário.

Conforme analisamos, a situação de São Gonçalo não difere de outros municípios brasileiros. E, embora a conquista desse direito perpasse a CF de 1988, passadas três décadas notamos que houve pouco avanço na garantia do mesmo para as crianças na Educação Infantil.

Diante desses dados, uma das ações do Ministério da Educação, visando garantir o acesso das crianças a creches e escolas, foi lançar o Programa Nacional de Reestruturação e Aquisição de Equipamentos para Rede Escolar Pública Infantil (Proinfância) pelo decreto da Resolução nº de 24 abril de 2007.

Outro retrocesso em termos de legislação foi a Emenda Constitucional no 95, de 15 de dezembro de 2016 que imobiliza por vinte anos os investimentos nas áreas sociais, em especial as da saúde e da educação. De acordo com Arelaro (2017, p. 214), os recursos destinados à educação foram reduzidos e, como apontam os estudos realizados pela Associação Nacional de Pesquisa em Financiamento da Educação (Fineduca) e pela Campanha Nacional pelo Direito à Educação, em 2016, “em vinte anos, os 18\% de recursos de impostos constitucionalmente vinculados à manutenção e desenvolvimento do ensino terão se transformado, no máximo, em 10\%”. Diante disso, a perspectiva é que não conseguiremos alcançar a universalização da educação básica e superior, dentre outras medidas.

Por fim, consideramos que após fazer este breve histórico da Educação Infantil no Brasil, apresentamos elementos para uma discussão mais densa acerca dos seus avanços e retrocessos. 
ARAUJO, Adriana Cabral Pereira; LEITE, Vania Finholdt Angelo. Conquistas e retrocessos do direito à educação: nas legislações e propostas de formação de professores

Neste sentido, além de favorecer à compreensão do tema os marcos legais vêm subsidiar o próximo tópico, no qual discutiremos sobre as propostas de formação continuada e as possibilidades que trazem de respeito à criança e seus direitos.

II Concepções de formação de professores: uma proposta que respeita a criança como sujeito de direitos?

Nos anos 1990, o Brasil passou por grandes transformações, tais como: a descentralização do sistema de saúde, a privatização de empresas públicas, a quebra dos monopólios estatais em áreas como petróleo, gás, energia e telecomunicações, a criação de agências reguladoras, a política industrial e a guerra fiscal. $\mathrm{Na}$ área da educação, como mencionamos anteriormente, teve a implementação da LDB 9.394/96, dos RCNEI, das DCNEI, dentre outros. Além disso, houveram, também, a transformação dos processos produtivos, a afirmação da sociedade da informação, o desenvolvimento de um estado mínimo, ou seja, mudanças que resultam em uma afirmação da hegemonia neoliberal.

Em função disso, a educação foi marcada por reformas educativas na perspectiva neoliberal e influenciada pelo processo de globalização. De acordo com Ball (2002), essas reformas foram implementadas tendo como referência duas tecnologias: o novo gerencialismo e a performatividade. O novo gerencialismo refere-se às mudanças ocorridas na atuação do Estado e na cultura dos serviços públicos. Trata-se, portanto, de uma nova forma de poder criada pela cultura empresarial competitiva. Quanto à performatividade, ela facilita o processo de monitoramento do Estado no trabalho das instituições públicas, principalmente porque envolve a combinação de descentralização da gestão, de responsabilização pelos resultados obtidos através de avaliações padronizadas e dos incentivos e premiações vinculadas às medidas de desempenho.

As reformas educativas traziam o argumento de que a escola estava em crise, demonstrado pelos baixos indicadores educacionais em relação ao desempenho escolar dos estudantes. Diante desses dados, organismos internacionais justificavam a necessidade de implementar a formação para os docentes e gestores da educação, atrelando-a a um discurso em defesa da profissionalização docente.

Embora a política educativa usasse a palavra profissionalização para conquistar a adesão dos educadores, a sua intenção era outra, pelo fato de atrelar outros termos a profissionalização, tais como: educador responsável, competente e competitivo. Eles denotam que o objetivo dessas políticas neoliberais era criar condições para que o Estado pudesse gerir o quadro de funcionários públicos do magistério (SHIROMA; EVANGELISTA, 2004). Para essas autoras, o que os 
organismos internacionais/formuladores de política desejavam construir bases de um novo ethos, identidade e nova cultura profissional.

Podemos verificar que os Referenciais de Formação de Professores (1999), as Diretrizes Curriculares para Formação de Professores (2001), o Programa de Formação Professor Alfabetizador (PROFA) em 2001, e o Proinfantil (2005) delineavam essa nova identidade profissional. Um perfil profissional centrado em competências, concebida como a mobilização de um conhecimento contextualizado, prático e voltado para a formação do profissional docente.

Esses programas/documentos indicavam que as competências propiciavam as situações de aprendizagem focadas em situações-problema ou no desenvolvimento de projetos, bem como possibilitam a interação dos diferentes conhecimentos. Acerca desse assunto, Dias e Lopes (2003) apontam que os referidos documentos pretendiam desenvolver um "como" ensinar, direcionando a formação para o desenvolvimento de capacidades de ação frente a uma situação específica e concreta. Isso é observado nos Referenciais de Formação de Professores (1999) que ao listar um repertório de competências desconsideravam os conhecimentos das disciplinas tradicionais, aproximando-se, assim, do movimento da eficiência social e da pedagogia dos objetivos.

Face ao exposto, concordamos com Dias e Lopes (2003) que essa concepção de prática profissional é distorcida, pois dificilmente podemos resolver os problemas que aparecem em uma situação concreta sem que se considere a complexa situação social. Frise-se, ainda, que para desenvolver as competências profissionais, a metodologia da formação docente proposta no Referencial de Formação de Professores (1999) focava em três aspectos: "na articulação teoria prática, na resolução de situações-problema e na reflexão sobre a atuação profissional" (BRASIL, 1999, p. 19).

Seguindo nesta mesma direção, ao discutir sobre a formação de professores Schöm (2000) nos apresenta três temas: o conceito de profissional, a relação teoria e prática e a reflexão, justamente os três aspectos mencionados anteriormente. O autor critica, porém, o paradigma de educação profissional baseado na racionalidade técnica, que se traduz por um modelo de aplicação da ciência aos problemas concretos da prática através da ciência aplicada. Ele propõe a epistemologia da prática como alternativa, tendo como ponto de referência as competências que se encontram subjacentes à prática dos bons profissionais.

Para desenvolver essa competência, uma das metodologias propostas no referencial (1999), é o da tematização da prática vinculada à concepção de professor reflexivo, em que a atuação docente é objeto de reflexão. A proposta do documento é que o professor ao tomar uma decisão 
reflita sobre ela. "Para planejar intervenções didáticas pertinentes e de qualidade, é preciso interpretar e analisar o contexto da realidade educativa" (BRASIL, 1999, p. 109).

Mesmo que o referencial proponha que as professoras interpretem e analisem o contexto da realidade educativa na sua reflexão, o excesso da prática reflexiva pode levar ao praticismo (PIMENTA, 2002), que se apoia na ideia de que bastaria a prática para se tonar um docente, excluindo a fundamentação teórica e as teorias afins da educação.

Outro pressuposto teórico do Referencial (1999) é o dos saberes experienciais defendido por Tardif (2002). Trata-se, portanto, de "um conjunto de saberes, atualizados, adquiridos e necessários no âmbito da prática da profissão docente e que não provêm das instituições de formação nem dos currículos" (TARDIF, 2002, p. 48). Eles são concebidos por "conhecimento construído "na" experiência articulado a uma reflexão sistemática sobre ela" nos referenciais (1999, p. 102).

Nessa perspectiva, a experiência de trabalho e os saberes oriundos da experiência docente cotidiana se constituem em alicerce da prática e da competência profissional, pois, por meio deles, o professor adquire e produz os próprios saberes profissionais. Ao ensinar, o docente mobiliza uma variedade de saberes, reutilizando-os, adaptando-os e transformando-os pelo e para o trabalho.

Dando seguimento na análise dos programas de formação, destacamos o ProInfantil, um programa de formação inicial de professores em nível de Ensino Médio, na modalidade Normal e semipresencial. Proposto pelo MEC no ano de 2005, ele foi oferecido em caráter emergencial para professores que atuavam em creches e pré-escolas públicas (ou em instituições privadas sem fins lucrativos), e que não possuíam a formação mínima exigida pela legislação. Essa formação inicial busca articular os conteúdos das diferentes áreas com as experiências dos professores, relacionando-as com discussões de teóricos. Observa-se que é um curso que se apoia na epistemologia da prática, na qual parte dos saberes experienciais dos professores são utilizados por eles, em seu espaço de trabalho, buscando relacioná-los com os referenciais teóricos. Mas, embora a formação mínima de professores, em nível médio, tenha sido mantida pela alteração da LDB com a Lei $\mathrm{n}^{\circ}$ 12.796, de 04 de abril de 2013, consideramos esta lei um retrocesso, pois a anterior torna necessária à formação de professores de Educação Infantil, em nível superior, no Curso de Pedagogia, por exemplo.

Nesses programas de formação inicial ou continuada de professores, percebemos que a concepção de criança não é mais aquela que requer somente o cuidado físico, mas que tem direito a uma educação direcionada a formação da pessoa. Enfim, a Educação Infantil vai se afastando da concepção de assistencialismo para educação, como um ato intencional que concebe a criança 
como ator no seu processo de aprendizagem. Uma infância que, nas palavras de Monção (2017, p. 163), é compreendida "como uma construção social e histórica, reconhecendo as instituições de educação infantil como contexto promotor da socialização das crianças pequenas em espaços coletivos, em parceria com suas famílias".

\section{Considerações finais}

Buscamos nesse ensaio compreender a trajetória da Educação Infantil brasileira nessas três décadas, analisando as políticas e algumas propostas de formação de professores, verificando em que medida elas garantem o direito à educação das crianças nesse período.

Percebemos que foi extenso o caminho para se chegar ao que temos hoje como direito constitucional garantido à criança na Educação Infantil. Um caminho marcado por retrocessos e avanços, sobretudo no que se refere às políticas públicas e às legislações que apontam em tal direção: a) a CF de 1988 que traz a educação básica obrigatória e gratuita como dever do Estado; b) a Lei no 9.394/96 definindo a Educação Infantil como primeira etapa da educação básica; c) O PNE (20142024) que propõe como meta a universalização da Educação Infantil na pré-escola e a ampliação de vagas nas creches para crianças até 3 anos; d) o RCNEI e as DCNEI que norteiam a prática pedagógica para educação infantil, considerando as especificidades das crianças, sejam elas sociais, econômicas, culturais, étnicas ou religiosas. No entanto, em 2016 tivemos ruptura do direito a criança com a EC no 95/2016 que congelou os investimentos nas áreas sociais, saúde e educação.

Em relação as propostas de formação de professores na perspectiva neoliberal, embora buscassem delinear um perfil profissional focado pelas competências, influenciadas pela subordinação a economia e a transformação da educação em mercadoria, elas mantiveram o respeito à criança e aos seus direitos. Isso ficou evidenciado nas análises dessas propostas que indicam que as práticas pedagógicas incluam, ouçam e respeitem a criança como ser participativo, ativo, criativo, produtor de culturas, dando visibilidade às suas produções, reconhecendo-as como atores sociais e de pleno direito.

Advertimos, porém, que mesmo que haja indicação do respeito à criança, isso dependerá da prática dos educadores com as crianças. Para tanto, há que se garantir espaços nas escolas para formação continuada de professores, centrados nas suas necessidades concretas e no seu fazer pedagógico, de forma que considere as condições e a realidade de trabalho da instituição em que atuam. Logo, é uma proposta que envolve a todos e que requer uma transformação dos professores e das escolas. 
Vale ressaltar que embora as propostas de formação de professores busquem transformar o perfil profissional dos professores, ao colocar em ação essas propostas, cabe a cada ator interpretá-las de acordo com suas condições materiais, a história da instituição, a cultura profissional (BALL et al., 2012). Isso significa que esses atores podem se engajar nessa proposta de formação ou modificá-la para harmonizar com a cultura da escola.

Em suma, os dados analisados levam-nos a reconhecer a fragilidade da garantia dos direitos à educação infantil já conquistados, tendo em vista que apontam a falta de ampliação na oferta de vagas, como vimos no observatório do II PNE, e, por conseguinte, não garantem o acesso da criança em creches e pré-escolas. Percebemos, portanto, que há muitas ações e políticas públicas que precisam ser revistas e implementadas, afinal, é um direito constitucional conquistado há três décadas que ainda não foi plenamente usufruído pelas crianças.

\section{Referências}

ABRAMOWICZ, ANETE; DE OLIVEIRA, FABIANA. Políticas públicas e direitos das crianças: uma reflexão a partir da perspectiva étnico-racial. Zero-a-seis (FLORIANÓPOLIS), v. 19, p. 290-307, 2017.

ARELARO, Lisete Regina Gomes. Avaliação das políticas de educação infantil no Brasil: avanços e retrocessos. Revista Zero-a-seis, Santa Catarina, v. 19, n. 36 p.206-222, jul/dez, 2017.

BALL, Stephen. Reformar escolas/reformar professores e os terrores da performatividade. Revista Portuguesa de Educação, Braga, Portugal. Ano V. v15, n.002, p-3-23, 2002.

BALL, Stephen, MAGUIRE, Meg, BRAUN, Annette. How schools do policy: policy enactments in secondary schools. Oxon: Routledge, 2012.

BRASIL. Constituição (1988). Constituição da República Federativa do Brasil. Brasília, DF: Senado Federal,1988.

BRASIL. Constituição (1988). Emenda Constitucional n. 53, de 19 de dezembro de 2006. Dá nova redação aos art. $7^{\circ}, 23,30,206,208,211$ e 212 da Constituição Federal e ao art. 60 do Ato das Disposições Constitucionais Transitórias. Brasília: 2006.

BRASIL. Constituição (1988). Emenda Constitucional n.95 de 15 dezembro de 2016. Altera o Ato das Disposições Constitucionais Transitórias, para instituir o Novo Regime Fiscal, e dá outras providências. Brasília: 2016.

BRASIL. Estatuto da criança e do adolescente: Lei Federal no 8069, de 13 de julho de 1990.

BRASIL. Lei de Diretrizes e Bases da Educação Nacional. Lei número 9394, 20 de dezembro de 1996. Disponível em: http://www.planalto.gov.br/ccivil 03/Leis/19394.htm Acesso em: 09 jun. 2018. 
BRASIL. Lei n. 12.796 de 04 de abril de 2013. Altera a Lei 9394/96 que estabelece as Diretrizes e Bases da Educaşão Nacional para dispor sobre a formação dos profissionais da educação e dar outras providências. Brasília/DF: 2013.

BRASIL. Ministério da Educação e do Desporto. Conselho Nacional de Educação. Diretrizes Curriculares Nacionais para a Educação Infantil. Parecer CEB nº. 022/98 aprovado em 17 de dezembro de 1998. Brasília, DF, 1998. Disponível em: www.mec.gov.br/cne/pdf/CEB22 1998.pdf. Acesso em: 09 jun. 2018.

BRASIL. Referencial curricular nacional para a educação infantil. Ministério da Educação e do Desporto, Secretaria de Educação Fundamental. Brasília: MEC/SEF, 1998.

BRASIL. Referenciais para formação de Professores. Secretaria de Educação Fundamental. Brasília: 1999.

BRASIL. Programa de Formação de Professores Alfabetizadores. Ministério da Educação. Secretaria de Educação Fundamental. Brasília: 2001.

BRASIL. Proinfantil: Programa de Formação Inicial para Professores em Exercício na Educação Infantil: diretrizes gerais / Ministério da Educação. Brasília: MEC, 2005.

BRASIL. Diretrizes Curriculares Nacionais para a Educação Infantil. Resolução no 05, de 17 de dezembro de 2009. Brasília: MEC/SEF, 2009.

BRASIL. Plano Nacional de Educação. Lei n. 13.005 de 25 de junho de 2014. Aprova o Plano Nacional de Educação - PNE e dá outras providências. Brasília: 2014.

BRASIL. Censo Escolar da Educação Básica 2016. Notas Estatísticas. Brasília: INEP, 2017.

CURY, C. R. J. A educação infantil como direito. In: MINISTÉRIO DA EDUCAÇÃO E DO DESPORTO. Subsidios para credenciamento e funcionamento de instituiçoes de educação infantil. Brasilia: MEC/SEF/COEDI, 1998. v. 2.

DIAS, Rosanne Evangelista; LOPES, Alice Casimiro. Competências na formação de professores no Brasil: o que (não) há de novo. Educação e Sociedade. Campinas, vol 24, n.85, p. 1155-1177, dez. 2003.

GATTI, Bernadete. Formação de professores no Brasil: características e problemas. Educaşão e Sociedade. Campinas, vol.31, n.113, p.1355-1379, out/dez. 2010.

KISHIMOTO, Tizuko Morchida. A pré-escola na república. Pro-Posições, Campinas, SP, v.1, n. 3(03), p. 55-56, dez. 1990.

MARCÍLIO, Maria Luiza. A roda dos expostos e a criança abandonada na História do Brasil. 1726-1950. In: FREITAS, Marcos Cezar de (Org.). História Social da Infância no Brasil. São Paulo: Cortez Editora, 1997.

MONÇÃO, Maria Aparecida Guedes. Cenas do cotidiano na educação infantil: desafios da integração entre cuidado e educação. Educação e Pesquisa, São Paulo, v. 43, n. 1, p. 161-176, jan./mar. 2017. 
Observatório do PNE. Disponível em: http://www.observatoriodopne.org.br/metas-pne/1educacao-infantil/indicadores. Acesso em: 06052018.

PIMENTA, Selma Garrido. Professor Reflexivo: construindo uma crítica.IN: Pimenta, Selma; GHEDIN, Evandro (org). Professor Reflexivo no Brasil: gênese de um conceito. 2. ed. São Paulo: Cortez, 2002.

PNE em movimento. Situação das Metas dos planos. [online]. Disponível em: http://simec.mec.gov.br/pde/graficopne.php. Acesso em: 20 jul. 2018.

ROSEMBERG, Fúlvia; MARIANO, CARMEM LÚCIA SUSSEL. A convenção internacional sobre os direitos da criança: debates e tensões. Cadernos de Pesquisa, v.40, n.141, p.693-728, set./dez. 2010.

SARMENTO, Manuel Jacinto. Visibilidade social e estudo da infância. In: VASCONCELLOS, Vera Maria Ramos de; SARMENTO, Manuel Jacinto. (org.) Visibilidade social e estudo social da infância. A Infância (In) visivel. Araraquara/SP: Junqueira e Marin, 2007.

SARMENTO, Manuel Jacinto. Gerações e alteridade: interrogações a partir da sociologia da infância. Educaşão e Sociedade, Campinas, vol. 26, n. 91, p. 361-378, Mai./Ago. 2005.

SCHÖN, Donald. Educando o profissional reflexivo um novo design para o ensino e aprendizagem. Porto Alegre: Artes Médica Sul, 2000.

SHIROMA, Eneida Oto; EVANGELISTA, Olinda. A colonização da utopia nos discursos sobre profissionalização docente. Perspectiva, Florianópolis, v. 22, n. 02, p. 525-545, jul./dez. 2004. Disponível em: http://www.ced.ufsc.br/nucleos/nup/perspectivas.html. Acesso em: 20 mar. 2018.

TARDIF, Maurice. Os professores diante do saber: esboço de uma problemática do saber docente. In: Saberes docentes e formação profissional. $4^{a}$ ed. Petrópolis, RJ: Vozes, 2002.

VIEIRA, Isabela. Defensoria Pública pedirá multa por alunos fora da creche e pré-escola no Rio. Agência Brasil, Rio de Janeiro, s/p, 20 jan. 2018. Disponível em:

http://agenciabrasil.ebc.com.br/educacao/noticia/2018-01/defensoria-publica-exigira-multapor-alunos-fora-da-pre-escola-e-creche-no . Acesso em: 20 abr. 2018.

Notas

\footnotetext{
${ }^{1} \mathrm{O}$ inciso IV do artigo 54 do ECA de 1990 ganhou nova redação dada pela Lei no 13.306, de 2016 que alterou na sua redação a faixa etária correspondente à Educação Infantil que era de 0 a 6 anos e passou a ser de 0 a 5 anos.

2 Redação alterada pela lei no 12.796, de 4 de abril de 2013, que alterou a idade de até 6 anos para até 5 anos na Educação Infantil.

3 O PNE (2001-2010) trazia também a educação como direito individual, como fator de desenvolvimento econômico e social, assim como, meio de combate à pobreza
} 


\section{Dialogia}

ARAUJO, Adriana Cabral Pereira; LEITE, Vania Finholdt Angelo. Conquistas e retrocessos do direito à educação: nas legislações e propostas de formação de professores

Recebido em: 30 mar. 2020/ Aprovado em: 25 jun. 2020

\section{$\underline{\text { Cite como }}$}

\section{(ABNT NBR 6023:2018)}

ARAUJO, Adriana Cabral Pereira; LEITE, Vania Finholdt Angelo. Conquistas e retrocessos do direito à educação: nas legislações e propostas de formação de professores. Dialogia, São Paulo, n. 35, p. 107-121, maio/ago. 2020. Disponível em: https://doi.org/10.5585/dialogia.n35.16914.

\section{American Psychological Association (APA)}

Araujo, A. C. P., \& Leite, V. F. A. (2020, maio/ago.). Conquistas e retrocessos do direito à educação: nas legislações e propostas de formação de professores. Dialogia, São Paulo, 35, p. 107-121. https://doi.org/10.5585/dialogia.n35.16914. 